\title{
Tartrazine Dye and Bovine Serum Albumin: the Influence of pH on Adsorption Process
}

\author{
Jackeline B. Brito, Gean P. S. Aguiar, Júlio C. J. Flores, Josmary R. Silva, Nara C. de Souza* \\ Grupo de Materiais Nanoestruturados, Universidade Federal de Mato Grosso, Barra do Garças, Mato Grosso, Brazil
}

\begin{abstract}
Multilayers from Tartrazine dye (Tart) alternated with bovine serum albumin (BSA) were successfully prepared and a uniform growth has been observed. The influence of two values of Tart solution $\mathrm{pH}$ ( 3 and 7.5) on adsorption process of this molecule on BSA monolayer at physiological $\mathrm{pH}$ was investigated using kinetics and isotherms of adsorption, as well as thermostimulated adsorption experiments. All effects found by the changing of the $\mathrm{pH}$ were explicated mainly taking into account the ionic attraction (Tart at $\mathrm{pH} 3$ ) and ionic repulsion (Tart at $\mathrm{pH}$ 7.5) that occurs during the adsorption process of Tart onto BSA monolayer.
\end{abstract}

Keywords Tartrazine Dye, Bovine Serum Albumin, Layer-By-Layer Deposition Method, Adsorption Process, Ph Influence

\section{Introduction}

Various heath problems are associated to the dyes, which are components of a lot of industrial products. Among the dyes, Tartrazine is very popular because is used in foodstuffs, cosmetics, textile, and medicines[1]. It has been also associated to diseases such as hyperactivity[2], asthma[3], and thyroid cancer[4]. Many studies have been carried out concerned to the Tartrazine dye (Tart) [5-8]. In special, the adsorption process of Tart has been investigated because its important role in applications, such as color removal from industrial effluents[9-12].

In this work we prepared Layer-by-Layer (LbL) films in order to investigate the interactions of Tart and proteins. Bovine serum albumin (BSA) was chosen because it is the most abundant protein in blood plasma, and works like a transport protein for several substances (dyes and bioactive molecules)[13,14]. The BSA has been focus of several studies for their properties, such as $\mathrm{pH}$-dependent binding[15] and interactions with phospholipids[16]. Besides that, BSA and human serum albumin, HSA, have a similarity of approximately $80 \%$ of their primary sequences[17]. This means that BSA and HSA are homologous proteins that should have very similar biological functions. Thus, as the Tartrazine is associated with various health problems, an investigation about the adsorption process of the dye and albumin can be used as an approach to analyze the biological process. Although there are several works on Tart and also

* Corresponding author:

ncsouza@ufmt.br (Nara C. de Souza)

Published online at http://journal.sapub.org/materials

Copyright (C) 2012 Scientific \& Academic Publishing. All Rights Reserved
BSA, we are not aware of any report about the preparation of multilayer systems and study of $\mathrm{pH}$ influence on adsorption process of Tart and BSA using the layer-by-layer (LbL) method. In this paper, we have not only studied the multilayer growth of Tart alternated with BSA, but also investigated the effect of $\mathrm{pH}$ on adsorption process of Tart on BSA monolayer focusing on the possible interactions associated to this process.

\section{Materials and Methods}

Tartrazine and BSA (fraction V, purity 96-100\%) from Acros Organics were used as received. The experimental film fabrication procedures are essentially the same as those described by Decher[18]. To build the multilayers, Tartrazine was alternated with $0.5 \mathrm{~g} / \mathrm{L}$ BSA diluted in ultrapure water. The $\mathrm{pH}$ of the BSA solution was adjusted to 7.5 (close to physiological $\mathrm{pH}$ ) by adding appropriate amounts of ammonium hydroxide. The final BSA solution was completely clear. The rinsing solution was ultrapure water with $\mathrm{pH}$ adjusted to 7.5. The Tartrazine solution was prepared to concentration of $0.5 \mathrm{~g} / \mathrm{L}$ by dissolution in ultrapure water. The $\mathrm{pH}$ of the Tartrazine and the rinsing solutions were adjusted to 7.5 (anionic solution) and 3 (cationic solution) by adding an ammonium hydroxide solution or $\mathrm{HCl}$ respectively. The films were adsorbed on BK7 optical glass and the cleaned procedures are essentially the same described by previous works[1,19] The adsorption of Tartrazine, which is proportional to absorbance, was monitored by measuring the UV-Vis absorption spectra with a double-beam Thermo Scientific spectrophotometer model Genesys 10 . 


\section{Results and Discussion}

We have employed the layer-by-layer (LbL) method to growth multilayers from BSA alternated with Tart (BSA/ Tart). Fig. 1 shows the absorbance at $425 \mathrm{~nm}$ versus the bilayer number, and an inset with the spectra of Tart solution and BSA/Tart ( $\mathrm{pH} 7.5 / \mathrm{pH} 7.5)$ films. A linear increase in the absorbance was observed, suggesting that the same amount of material was adsorbed in each deposition cycle. The spectra (inset in Fig. 1) are essentially the same as those found in the literature for the Tartrazine[1,20]. The maximum absorption wavelength $\lambda$ max of Tart molecules appears at $408 \mathrm{~nm}$ in aqueous solution (symbol line) and $425 \mathrm{~nm}$ in LbL films. These results reveal a $\lambda$ max shift $(\Delta \lambda$ $=17 \mathrm{~nm}$ ) to red for the BSA/Tart bilayer in relation to the Tartrazine aqueous solution[1], indicating that the dye molecules join in J-aggregates with in-line transition dipoles[21]. The capacity of forming multilayers of the BSA and Tart reveals clearly that there are interactions between these two kinds of molecules, which permit the assembly of films[1].

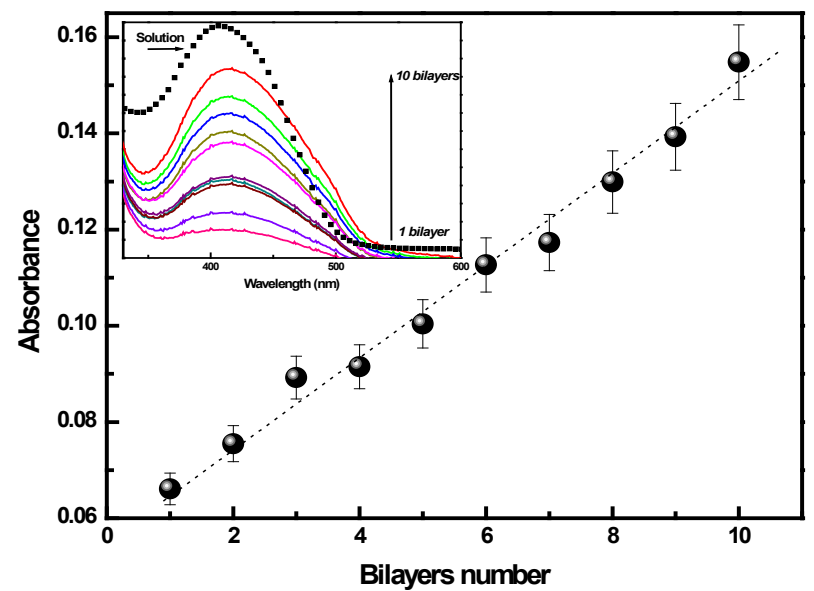

Figure 1. Absorbance at $425 \mathrm{~nm}$ versus bilayer number for BSA/Tart LbL films on BK7 glass. The experiment was carried out at $\mathrm{pH} 7.5$ for both Tart and BSA. Each experimental point is the average of measurements of three films fabricated under identical conditions. The inset shows the $\mathrm{UV}-\mathrm{V}$ is spectra of the Tart solution and also for LbL multilayers

Solution $\mathrm{pH}$ is one of the parameters that can influence on the interaction of Tartrazine and BSA during the adsorption process[22]. Fig. 2 shows the adsorption kinetics curves of BSA/Tart bilayers at different $\mathrm{pH}$ values. The curves were obtained by depositing Tart at $\mathrm{pH} 3$ or 7.5 on BSA at pH 7.5 using an immersion time of 3 min for Tart solution. We can observe that Tart at $\mathrm{pH} 3$ presents the maximum absorbance larger than at $\mathrm{pH}$ 7.5. Moreover, the absorbance at $\mathrm{pH} 7.5$ achieves the saturation at ca. $2 \mathrm{~s}$, and at pH 3 at ca. $120 \mathrm{~s}$. We can consider that the Tart molecules at $\mathrm{pH} 7.5$ are repelled from away the BSA surface, so the saturation of Tart molecules on BSA monolayer surface should occur quickly, because only some Tart molecules close to BSA surface can adsorb by other interactions different of that ionic one. That is, the others interactions can overcome the ionic repulsion close to BSA monolayer surface[23]. On the other hand, in the case of Tart molecules in $\mathrm{pH} 3$ the ionic forces dominate the adsorption process.

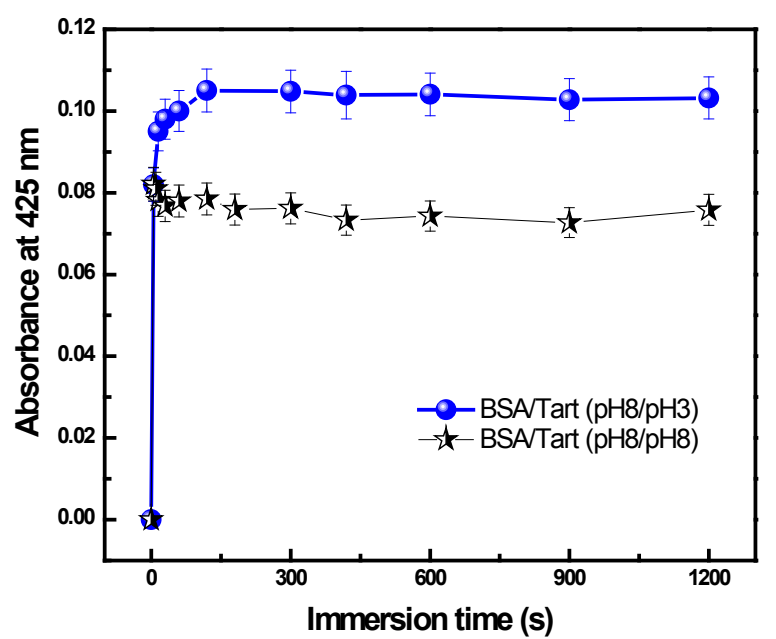

Figure 2. Absorbance at $425 \mathrm{~nm}$ versus immersion time for BSA/Tart $\mathrm{LbL}$ film at different $\mathrm{pH}$ values. The solid line is a guide for the eye

We have performed adsorption isotherm experiments by depositing Tart at pH 3 (Fig. 3) and pH 7.5 (Fig. 4) onto BSA monolayer with immersion time of 10 minutes for BSA and 3 min for Tart solution. As shown in the Fig. 3, we have observed three different regimes for the absorbance. For small concentrations, the absorbance increase fast and linearly, after that achieve a constant value, and thus increases again. The saturation absorbance suggests that a whole layer was achieved and, as a result, the monolayer surface tends to repel the solute because all active sites for adsorption already were filled. The growth after saturation can be indicates the formation of a second monolayer[24].

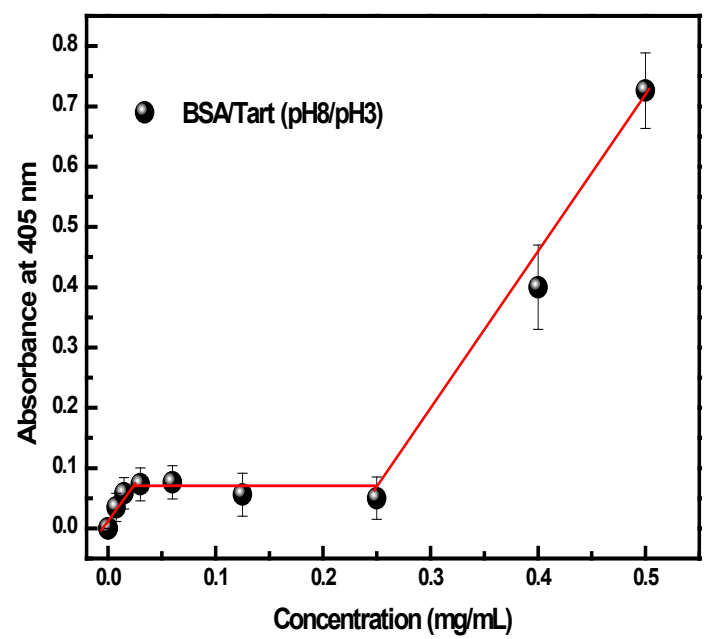

Figure 3. Adsorption isotherm for Tart $(\mathrm{pH} 3)$ adsorbed on BSA monolayer $(\mathrm{pH} 8)$ with immersion time of $3 \mathrm{~min}$. The solid line is a guide for the eye

Fig. 4 shows the adsorption isotherm for Tart at $\mathrm{pH}$ 7.5. It is noted a different behavior of this isotherm in comparison to that showed in Fig. 3. We can observe only an increase of absorbance and, after that, a saturation. This can be attributed 
to ionic repulsion between Tart and BSA molecules when Tart is at $\mathrm{pH} 7.5$ and BSA monolayer at $\mathrm{pH}$ 7.5. In this situation, there is a competition between the attractive interactions and the ionic repulsion. Even the concentration is increased, it does not contribute to increase the Tart adsorbed molecule amount, and the saturation is achieved at lower value that that found for Tart at $\mathrm{pH} 3$.

In order to determine the activation energy associated to the adsorption process of Tart on BSA monolayer for the different $\mathrm{pH}$ values, we have performed thermostimulated adsorption experiments. Fig. 5 shows the Arrhenius plot from absorbance at $425 \mathrm{~nm}$ as a function of temperature for Tart and BSA solutions.

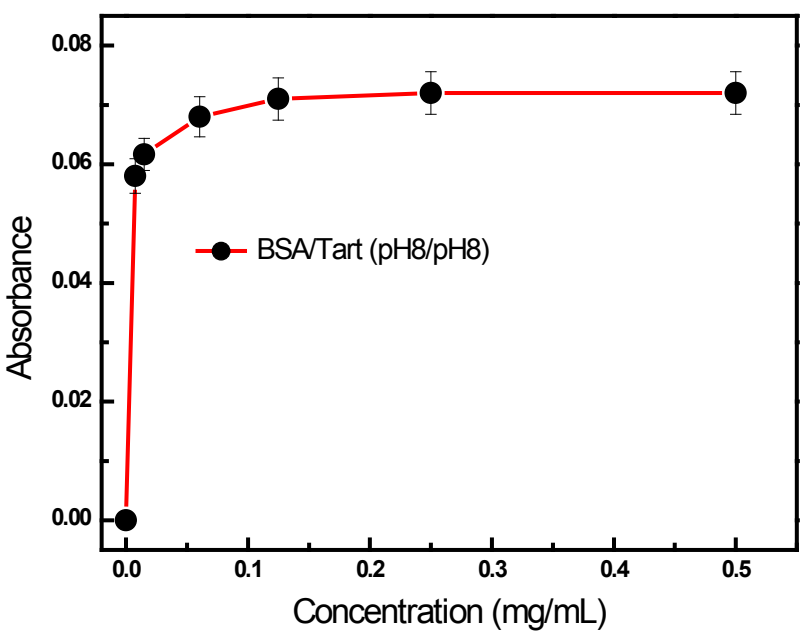

Figure 4. Adsorption isotherm for Tart $(\mathrm{pH}$ 8) adsorbed on BSA monolayer ( $\mathrm{pH}$ 8) with immersion time of $3 \mathrm{~min}$. The solid line is a guide for the eye

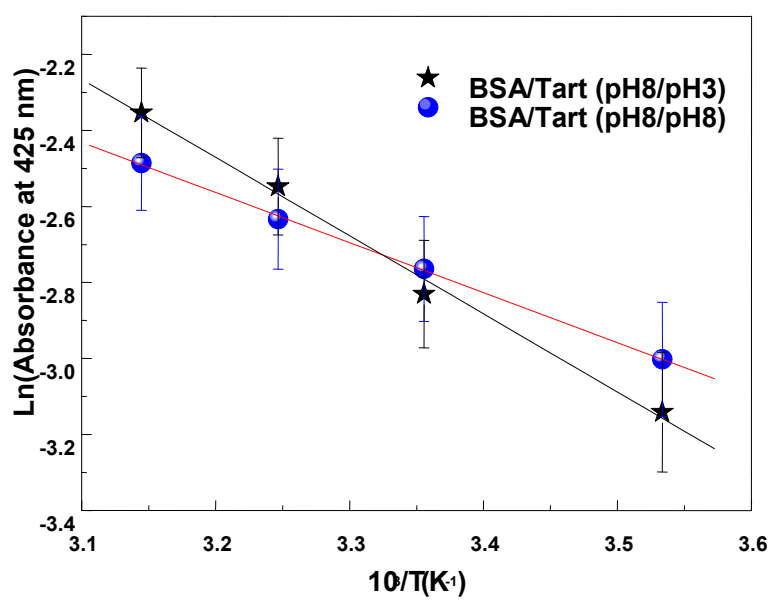

Figure 5. Arrhenius plot for adsorption process of Tart ( $\mathrm{pH} 8$ and 3) adsorbed onto BSA monolayer ( $\mathrm{pH} 8$ )

The activation energies were found be about $2.6 \mathrm{kcal} / \mathrm{mol}$ for $\mathrm{BSA} /$ Tart $(\mathrm{pH} 7.5 / \mathrm{pH} 7.5)$ and $4.1 \mathrm{kcal} / \mathrm{mol}$ for $\mathrm{BSA} /$ Tart $(\mathrm{pH} 7.5 / \mathrm{pH} 3)$. The higher activation energy observed for the Tart at $\mathrm{pH} 3$ in comparison with the Tart at $\mathrm{pH} 7.5$ can be explained taking into account that at the first one there is an ionic attraction contribution that increases the interaction magnitude between the Tart and BSA molecules. However, when the $\mathrm{pH}$ of Tart is 7.5, the ionic repulsion dominated the process and the adsorption of Tart can be governed by hydrogen or van der Waals interactions. The values of activation energy are consistent with those found for the Eosin and BSA system[15].

\section{Conclusions}

We have successfully prepared multilayer films from Tart and BSA and shown that the Tart interacts depends on the conditions of the solution $\mathrm{pH}$ used in the preparation of films. The adsorption process of Tart at $\mathrm{pH} 7.5$ has not only adsorption rate faster, but also maximum adsorbed amount and activation energy lower than at $\mathrm{pH} 3$. All this results was attributed mainly to ionic attraction associated to Tart at $\mathrm{pH} 3$ and ionic repulsion associated to Tart at $\mathrm{pH} 7.5$ when it is adsorbed on the BSA at $\mathrm{pH}$ 7.5. The possibility of forming multilayer films based on dyes and proteins can be used in investigations of biological sensors, whereas the knowledge of influence of $\mathrm{pH}$ on adsorption process of Tart on BSA monolayer may be useful to studies of interactions associated to health problems.

\section{ACKNOWLEDGEMENTS}

This work was supported by CNPq and CAPES.

\section{REFERENCES}

[1] N.C. de Souza, J.C.J.Flores, J.R. Silva, Layer-by-layer films from tartrazine dye with bovine serum albumin. Chemical Physics Letters 484 (2009) 33-36.

[2] A. Thuvander, Hypersensitivity to azo coloring agents. Tartrazine in food may cause rash and asthma. Lakartidningen, 92 (4) (1995) 296-298.

[3] C. Collins-Williams, Clinical spectrum of adverse reactions to tartrazine, J. Asthma Rev, 22 (3) (1985) 139-143.

[4] J.F. Borzelleca, J.B. Hallagan, Food Chem, Chronic toxicity/carcinogenicity studies of FD \& C yellow $n^{\circ} 5$ (tartrazine) in rats. Toxicol, 26 (3) (1988) 179-187.

[5] J.J. Berzas, J. Rodríguez Flores, M.J. Villaseñor Llerena, N. Rodríguez Fariñas, Spectrophotometric resolution of ternary mixtures of Tartrazine, Patent Blue V and Indigo Carmine in commercial products. Analytica Chimica Acta, 391 (1999) 353-364.

[6] N. Tugcu, S.M. Cramer, The effect of multi-component adsorption on selectivity in ion exchange displacement systems, Journal of Chromatography A 1063 (2005) 15-23.

[7] T. Tanaka, O. Takahashi, S. Oishi, A. Ogata, Effects of tartrazine on exploratory behavior in a three-generation toxicity study in mice. Reproductive Toxicology 26 (2008) 156-163. 
[8] M.J. Culzonia, H.C. Goicoechea, G. A. Ibañez, V.A. Lozano, N.R. Marsili, A.C. Olivieri, A.P. Pagani, Second-order advantage from kinetic-spectroscopic data matrices in the presence of extreme spectral overlapping. A multivariate curve resolution alternating least-squares approach. Analytica Chimica Acta, 614 (2008) 46-57.

[9] M. Wawrzkiewicz, Z. Hubicki, Removal of tartrazine from aqueous solutions by strongly basic polystyrene anion exchange resins. Journal of Hazardous Materials, 164 (2009) 502-509.

[10] N. Dizge, C. Aydiner, E. Demirbas, M. Kobya, S. Kara, Adsorption of reactive dyes from aqueous solutions by fly ash: Kinetic and equilibrium studies. Journal of Hazardous Materials, 150 (2008) 737-746.

[11] L. Monser, N. Adhoum, Tartrazine modified activated carbon for the removal of $\mathrm{Pb}(\mathrm{II}), \mathrm{Cd}(\mathrm{II})$ and $\mathrm{Cr}(\mathrm{III})$. Journal of Hazardous Materials, 161 (2009) 263-269.

[12] A. Mittal, L. Kurup, J. Mittal, Freundlich and Langmuir adsorption isotherms and kinetics for the removal of Tartrazine from aqueous solutions using hen feathers. Journal of Hazardous Materials, 146 (2007) 243-248.

[13] N. Holm, Aggregation and fibrillation of bovine serum albumin, Biochim. Biophys. Acta, 1774, (2007) 1128-1138.

[14] V. Vetri, L. Librizzi, L. Leone, V. Militello, Thermal aggregation of bovine serum albumin at different $\mathrm{pH}$ : comparison with human serum albumin. Eur. Biophys. J, 36 (2007) 717-725.

[15] D. Gao, Y. Tian, F. Liang, D. Jin, Y. Chen, H. Zhang, A. Yu, Investigation on the $\mathrm{pH}$-dependent binding of Eosin $\mathrm{Y}$ and bovine serum albumin by spectral methods. Journal of $\mathrm{Lu}-$ minescence, 127 (2007) 515-522.

[16] N.C. de Souza, W. Caetano, R. Itri, C.A. Rodrigues, O.N. Oliveira Jr., J.A. Giacometti, M. Ferreira, Interaction of small amounts of bovine serum albumin with phospholipid monolayers investigated by surface pressure and atomic force microscopy. Journal of Colloid and Interface Science 297 (2006) 546-553.

[17] J.V. Jayabharathi, M.P. Thanikachalam, Mechanistic investigation on binding interaction of bioactive imidazole with protein bovine serum albumin - A biophysical study, Spectrochimica Acta Part A,79 (2011) 502-507.

[18] G. Decher, Fuzzy Nanoassemblies: Toward Layered Polymeric Multicomposites. Science, 277 (1997) 1232-1237.

[19] N. C. de Souza, J. R. Silva, R. Di Thommazo, M. Raposo, D. T. Balogh, J. A. Giacometti, O. N. Oliveira Jr, Influence of Solution Treatment on the Adsorption and Morphology of Poly(o-methoxyaniline) Layer-by-Layer Films. J. Phys. Chem. B, 108 (2004) 13599-13606.

[20] R. Li, Z.-Tao Jiang, Y.-Hao Liu, Direct Solid-phase Spectrophotometric Determination of Tartrazine in Soft Drinks Using $\beta$-Cyclodextrin Polymer as Support. Journal of Food and Drug Analysis. 16 (5) (2008) 91-96.

[21] M. C. Petty, Langmuir-Blodgett films: An Introduction, Cambridge University Press, 1996.

[22] M. Raposo, R.S. Pontes, L.H.C. Mattoso, O.N. Oliveira Jr., Kinetics of Adsorption of Poly(o-methoxyaniline) Self- Assembled Films. Macromolecules 30 (1997) 6095-6101.

[23] O. N. Oliveira Jr., J.-A He, V. Zucolotto, S. Balasubramanian, L. Li, H.S Nalwa, J. Kumar, S. K. Tripathy, In Handbook of Polyelectrolytes; Tripathy, S. K., Kumar, J., Nalwa, H. S., Eds.; American Scientific Publishers: Los Angeles, 2002; Vol. 1 Layer-by-Layer Polyelectrolyte Films for Electronic and Photonic Applications, pp 1-37.

[24] C. H. Giles, A. P. D’Silva, J. A. Baston, A general treatment and classification of the solute adsorption isotherm part. II. Experimental interpretation. Journal of Colloids and Interface Science, 47 (1974) 766-778. 